\title{
GUÉRIN (Pierre), GAST (Marceau), GUÉRIN (Madeleine), GUÉRIN (Claudie) (dir.), Sur les pas de
} Freinet

Paris : Ibis Press, 2008. 248 p.

Marie-Laure Viaud

\section{OpenEdition}

Journals

Édition électronique

URL : https://journals.openedition.org/histoire-education/1809

DOI : 10.4000/histoire-education. 1809

ISSN : 2102-5452

Éditeur

ENS Éditions

Édition imprimée

Date de publication : 1 janvier 2009

Pagination : 134-135

ISBN : 979-2-7342-1142-6

ISSN : 0221-6280

\section{Référence électronique}

Marie-Laure Viaud, « GUÉRIN (Pierre), GAST (Marceau), GUÉRIN (Madeleine), GUÉRIN (Claudie) (dir.), Sur les pas de Freinet », Histoire de l'éducation [En ligne], 121 | 2009, mis en ligne le 20 mai 2009, consulté le 20 mai 2021. URL : http://journals.openedition.org/histoire-education/1809 ; DOI : https:// doi.org/10.4000/histoire-education.1809

Ce document a été généré automatiquement le 20 mai 2021.

(c) Tous droits réservés 


\section{GUÉRIN (Pierre), GAST (Marceau), GUÉRIN (Madeleine), GUÉRIN (Claudie) (dir.), Sur les pas de Freinet}

Paris : Ibis Press, 2008. 248 p.

Marie-Laure Viaud

\section{RÉFÉRENCE}

GUÉRIN (Pierre), GAST (Marceau), GUÉRIN (Madeleine), GUÉRIN (Claudie) (dir.), Sur les pas de Freinet, Paris : Ibis Press, 2008. 248 p.

1 Cet ouvrage, composé d'une quarantaine de témoignages, trace le portrait de Pierre Guérin, instituteur adepte des méthodes de Célestin Freinet, qui fut un des promoteurs de l'utilisation de l'audiovisuel en classe.

2 En 1949, Pierre Guérin découvre, lors d'un congrès du mouvement Freinet, l'enregistrement sur disque de cire puis, l'année suivante, le magnétophone à fil. À partir de 1957, il introduit le magnétophone dans sa classe pour permettre à ses élèves de réaliser des productions sonores, destinées notamment à leurs correspondants. Très vite, les élèves produisent également des séquences d'émissions de radio, diffusées par Jean Thévenot dans les émissions «Aux quatre vents " puis "Chasseurs de sons », sur France culture ${ }^{1}$. Des collègues font alors part à $\mathrm{P}$. Guérin de leur souhait de faire profiter leurs élèves de ces réalisations: c'est, en 1961, la naissance des BT son (Bibliothèques de travail sonore), qui deviennent rapidement des ensembles multimédias dont la brochure d'accompagnement comprend des diapositives en couleurs, des documents sonores et des documents écrits. Deux cent vingt-cinq titres seront diffusés jusqu'en 1996.

3 Dès 1962, P. Guérin, quelques autres instituteurs Freinet et leurs élèves interviewent des scientifiques, comme Paul-Émile Victor sur l'Arctique, Haroun Tazieff sur les volcans ou Yves Coppens sur la préhistoire, l'idée étant de "prendre des informations 
au "top niveau" pour nous éviter de commettre de grossières erreurs dans nos explications aux enfants ». Quelques-uns d'entre eux lancent, dans les années 1970, un enseignement des sciences partant des représentations initiales des élèves et fondé sur le tâtonnement et l'expérimentation. Cela les conduit à créer de nombreux outils destinés à promouvoir cette approche, notamment de nombreuses Bibliothèques de travail sciences.

4 Grâce au talent de conteur de certains témoins, plusieurs contributions de cet ouvrage dépassent le simple hommage et font revivre une époque, comme, par exemple, «La naissance d'une BT son », p. 56-70, ou «En famille», p. 211-223. Ainsi, le portrait de Pierre Guérin est aussi celui d'un militant qui, pendant l'essentiel de son temps libre, s'enferme dans son sous-sol transformé en studio de montage ou sillonne la France avec sa voiture bourrée de matériel sonore. De façon plus générale, ce livre permet de comprendre ce que pouvait être le militantisme des enseignants du mouvement Freinet. Par exemple, le récit de deux enseignants embarqués, pendant l'été 1974, sur un chalutier montre l'intensité de leur investissement et l'ampleur du travail nécessaire à la réalisation d'une BT son de très grande qualité : pour bien connaitre le travail des marins et enregistrer des témoignages sur leur vie sortant du discours convenu, ces enseignants ont partagé cette vie pendant deux semaines, condition nécessaire, disent-ils, " pour témoigner auprès des enfants au plus près de la réalité » (p. 56).

5 Cet ouvrage s'adresse à ceux qui s'intéressent à l'histoire du mouvement Freinet, du militantisme, de l'enseignement des sciences à l'école ou de l'utilisation des documents sonores en classe. Néanmoins, les textes présentés sont de qualité très diverse. Quelques témoignages passionnants côtoient des discours d'hommage sans grand intérêt. D'un texte à l'autre, les redites sont nombreuses. Un ouvrage plus construit aurait peut-être pu gagner un public plus large.

\section{NOTES}

1. Ils fournissent un total de 658 enregistrements pour des émissions de radio.

\section{AUTEURS}

MARIE-LAURE VIAUD 